\title{
Geração de renda e interdependência regional entre os estados do Sul e o restante do Brasil ${ }^{\dagger}$
}

\author{
Umberto Antonio Sesso Filho* \\ Antonio Carlos Moretto* \\ Rossana Lott Rodrigues ${ }^{* * *}$ \\ Paulo Rogério Alves Brene ${ }^{* * * *}$ \\ Joaquim José Martins Guilhoto****
}

\begin{abstract}
RESUMO - O objetivo da pesquisa foi analisar a capacidade de geração de renda setorial do sistema inter-regional de insumo-produto com quatro regiões, Paraná, Santa Catarina, Rio Grande do Sul e Restante do Brasil, e seus impactos locais e inter-regionais em 2004. Os principais resultados mostraram que: a) existem setores-chave comuns entre as regiões que apresentam baixo efeito transbordamento, todos pertencentes ao comércio e serviços; b) existe maior interação econômica entre os estados da Região Sul com o Restante do país do que com os estados da mesma região; c) as cadeias produtivas das atividades Refino de petróleo, Indústria automobilística, Agroindústria (Alimentos e Bebidas e Produtos do fumo) e Artigos do vestuário e acessórios são responsáveis pela maior parte dos fluxos inter-regionais de bens e serviços para consumo intermediário.
\end{abstract}

Palavras-chave: Insumo-produto. Renda. Região Sul.

\section{INTRODUÇÃO}

A reestruturação produtiva da economia brasileira ocorrida a partir da década de 1990 em conjunto com a desconcentração industrial e a maior inserção do Brasil no comércio internacional promoveram o aumento dos fluxos de bens e serviços entre as regiões do país. A

\footnotetext{
† Os autores agradecem à Fundação Araucária e ao CNPq pela ajuda financeira.

* Doutor em economia aplicada pela Escola Superior de Agricultura Luiz de Queiroz/Universidade de São Paulo. É professor do Programa de Pós-Graduação em Economia Regional do Departamento de Economia da Universidade Estadual de Londrina e pesquisador do CNPq. Endereço eletrônico: umasesso@uel.br.

** Doutor em economia aplicada pela Escola Superior de Agricultura Luiz de Queiroz/Universidade de São Paulo. É professor do Programa de Pós-Graduação em Economia Regional do Departamento de Economia da Universidade Estadual de Londrina. Endereço eletrônico: acmoretto@uel.br.

*** Doutora em economia aplicada pela Escola Superior de Agricultura Luiz de Queiroz/Universidade de São Paulo. É professora do Programa de Pós-Graduação em Economia Regional do Departamento de Economia da Universidade Estadual de Londrina. Endereço eletrônico: rlott@uel.br.

**** Professor do Departamento de Economia da Universidade Estadual do Norte do Paraná. Endereço eletrônico: paulobrene@uenp.edu.br.

***** Doutor em economia pela Universidade de Illinois. É professor titular do Departamento de Economia da Faculdade de Economia, Administração e Contabilidade da Universidade de São Paulo, e professor no Laboratório de Aplicações de Economia Regional da Universidade de Illinois. Endereço eletrônico: guilhoto@usp.br.
} 
maior interdependência entre setores de diferentes regiões faz com que o aumento da produção em um determinado setor da economia tenha efeitos sobre produção, emprego e renda na economia local e em outras partes do país em setores relacionados direta ou indiretamente à atividade econômica que sofreu o impacto inicial do aumento de sua demanda final. Assim, torna-se importante conhecer o efeito transbordamento, o efeito indireto do aumento de produção de um determinado setor fora de sua região de origem.

Para analisar os efeitos locais e inter-regionais sobre a renda foi construído um sistema inter-regional de insumo-produto com quatro regiões, Paraná, Santa Catarina, Rio Grande do Sul e Restante do Brasil. Este sistema possui os fluxos de bens e serviços entre as regiões em análise, tornando possível estimar a geração de renda decorrente de impactos da demanda final setorial sobre todo o sistema econômico.

Considerando as transformações da economia analisadas anteriormente, o objetivo da pesquisa foi analisar a capacidade de geração de renda dos setores da economia e seus impactos locais e inter-regionais. Especificamente, pretende-se: a) calcular a geração de renda para os setores da economia dentro do sistema inter-regional Sul-Restante do Brasil; b) identificar os setores-chave com maior geração de renda em cada região e aqueles com maior efeito transbordamento.

O texto possui cinco seções incluindo esta introdução. A segunda seção apresenta, rapidamente, a distribuição regional da renda e outras pesquisas sobre a dinâmica da renda e o efeito transbordamento, enquanto a terceira descreve a metodologia de cálculo e fonte dos dados da pesquisa. A seção quatro mostra os resultados e discussão e a quinta seção as principais conclusões.

\section{DISTRIBUIÇÃO REGIONAL DA RENDA}

Em 2004, de acordo com IBGE (2009), a Região Sul participou com cerca de 18\% do Produto Interno Bruto (PIB) nacional e deteve 14,6\% da população, apresentando o segundo maior PIB per capita depois da Região Sudeste, inclusive maior do que o PIB per capita brasileiro.

Embora agrupados numa mesma região, os três estados do Sul apresentam diferenças, tanto entre si, quanto em relação à economia nacional, no que se refere aos níveis de industrialização, tecnológico e em fatores relacionados aos mercados de insumos, o que se reflete nas suas estruturas produtivas e, consequentemente, na geração e distribuição de renda. Assim, verificou-se maior importância da Agropecuária e Construção para o estado do Paraná e da Agropecuária e Indústria de transformação para os estados de Santa Catarina e Rio Grande do 
Sul do que para a economia nacional. O agronegócio assumiu papel fundamental na economia regional, uma vez que a participação da Agropecuária variou entre 13,61\% a 18,39\% no valor adicionado bruto, muito maior do que os 9,51\% do Brasil (IBGE, 2009). Considerando que parte da indústria de transformação também pertence ao agronegócio, este macrossetor se apresentou como o mais importante para a Região Sul em 2004.

A análise da distribuição regional da renda pode ser complementada com a adição dos efeitos dos fluxos de comércio inter-regionais sobre esta variável. O presente artigo pretende, deste modo, complementar esta análise, a exemplo de outros, como o de Moretto et al. (2008), de Sesso Filho, Rodrigues e Moretto (2007), de Porsse, Peixoto e Palermo (2008), para citar apenas alguns exemplos.

\section{METODOLOGIA}

\subsection{FONTE DOS DADOS E CONSTRUÇÃO DO SISTEMA INTER-REGIONAL SUL- RESTANTE DO BRASIL}

A partir dos dados publicados pelo Instituto Brasileiro de Geografia e Estatística (IBGE, 2009) e seguindo a metodologia de Guilhoto e Sesso Filho (2005a) foi estimada a matriz de insumo-produto nacional para o ano de 2004. Posteriormente, foi usada a metodologia descrita em Guilhoto e Sesso Filho (2005b) para construir o sistema inter-regional com quatro regiões, Paraná, Santa Catarina, Rio Grande do Sul e Restante do Brasil, e cinquenta e cinco setores, cuja metodologia está exposta detalhadamente em Rodrigues, et al. (2010).

\subsection{GERAÇÃO DE RENDA}

A partir dos coeficientes diretos e da matriz inversa de Leontief, é possível estimar, para cada setor da economia, quanto é gerado, direta e indiretamente, de renda por unidade monetária produzida para a demanda final (MILLER; BLAIR, 2009):

$$
G R_{j}=\sum_{i=1}^{n} l_{j} r_{i}
$$

Em que $G R_{j}$ é o gerador que mede o impacto total direto e indireto sobre a renda causado pela variação de uma unidade monetária da demanda final; $l_{j}$ é o $\ddot{j}$-ésimo elemento da matriz inversa de Leontief e $r_{i}$ é o coeficiente direto de renda (renda dividida pela produção setorial). 


\section{RESULTADOS E DISCUSSÃO}

O cálculo da geração de renda é realizado para a variação de mil reais na demanda final de cada setor e os resultados apresentados em reais de 2004. A renda considerada se constitui na soma de remunerações, Excedente Operacional Bruto (EOB) e rendimento de autônomos dos setores da economia. É importante observar que os resultados consideram os efeitos diretos e indiretos sobre a renda em uma análise de equilíbrio geral, o que implica que o aumento da demanda final de um setor tem impacto sobre este (efeito direto), sobre outros setores da economia da própria região (consumo intermediário intrarregional) e sobre outras regiões, via fluxos de bens e serviços inter-regionais (efeito indireto).

$\mathrm{Na}$ Tabela 1 estão apresentados os valores absolutos das médias de geração de renda. Considerando a variação de mil reais na demanda final setorial, em média, os setores do Paraná gerariam, em 2004, R \$ 786 de renda (remunerações das pessoas ocupadas, excedente operacional das empresas e rendimento dos autônomos), sendo que destes, $\mathrm{R} \$ 632$, ou seja, $80 \%$, permaneceriam no próprio estado, R $\$ 12$ no estado de Santa Catarina, R $\$ 13$ no Rio Grande do Sul e R\$130,17\%, no Restante do Brasil, em valores de 2004. O maior valor absoluto total de geração de renda (Tabela 1) pertenceria a Santa Catarina, $\mathrm{R} \$ 802$, e, em segundo lugar, ao Paraná.

TABELA 1 - MÉDIAS DA GERAÇÃO DE RENDA DOS SETORES DA ECONOMIA PARA A VARIAÇÃO DE R\$ 1 MIL DA DEMANDA FINAL SETORIAL, EM R\$ DE 2004

\begin{tabular}{l|r|r|r|r|r}
\hline & Paraná & $\begin{array}{c}\text { Santa } \\
\text { Catarina }\end{array}$ & $\begin{array}{c}\text { Rio Grande } \\
\text { do Sul }\end{array}$ & $\begin{array}{c}\text { Restante } \\
\text { do Brasil }\end{array}$ & Total \\
\hline Paraná & 632 & 12 & 13 & 130 & 786 \\
Santa Catarina & 20 & 630 & 18 & 133 & 802 \\
Rio Grande do Sul & 12 & 10 & 652 & 106 & 781 \\
Restante do Brasil & 13 & 7 & 13 & 738 & 770 \\
\hline
\end{tabular}

FONTE: Cálculo dos autores.

Os maiores valores de transbordamento da geração de renda dos setores foram obtidos no sentido dos estados da Região Sul para o Restante do Brasil variando, em média, de 14\% a 17\%. O Rio Grande do Sul apresentou o menor percentual de transbordamento dos estados da Região Sul, pois cerca de $84 \%$ da geração de renda permaneceriam na própria região O transbordamento na direção Restante do Brasil-Região Sul variou entre 1\% e 2\%, em média (Tabela 1). Quanto maior o efeito transbordamento da geração de renda dos setores de uma região, maior a dependência de insumos desta região em relação às outras regiões para alimentar seu sistema econômico, causando, assim, geração de renda fora da região de origem do impacto inicial da variação da demanda final.

As Tabelas 2, 3, 4 e 5 apresentam os resultados da geração de renda e do transborda- 
mento para os setores dos estados do Paraná, Santa Catarina, Rio Grande do Sul e Restante do Brasil.

TABELA 2 - GERAÇÃO DE RENDA DOS SETORES DO PARANÁ PARA A VARIAÇÃO DE R\$ 1 MIL DA DEMANDA FINAL DOS SETORES, EM R\$ DE 2004

\begin{tabular}{|c|c|c|c|c|c|c|}
\hline Setor & Paraná & $\begin{array}{c}\text { Santa } \\
\text { Catarina }\end{array}$ & $\begin{array}{c}\text { Rio } \\
\text { Grande } \\
\text { do Sul }\end{array}$ & $\begin{array}{c}\text { Restante } \\
\text { do } \\
\text { Brasil }\end{array}$ & Total & $\begin{array}{c}\text { Transbor- } \\
\text { damento } \\
(\%)\end{array}$ \\
\hline 1 Agricultura, silvicultura, exploração florestal & 709 & 11 & 13 & 103 & 835 & 15 \\
\hline 2 Pecuária e pesca & 627 & 19 & 14 & 155 & 815 & 23 \\
\hline 3 Petróleo e gás natural & 759 & 4 & 4 & 54 & 822 & 8 \\
\hline 4 Minério de ferro & 731 & 4 & 3 & 102 & 840 & 13 \\
\hline Outros da indústria extrativa & 711 & 7 & 4 & 73 & 796 & 11 \\
\hline 6 Alimentos e Bebidas & 501 & 23 & 27 & 255 & 805 & 38 \\
\hline Produtos do fumo & 698 & 8 & 9 & 75 & 790 & 12 \\
\hline Têxteis & 623 & 11 & 13 & 135 & 783 & 20 \\
\hline 9 Artigos do vestuário e acessórios & 514 & 47 & 15 & 239 & 815 & 37 \\
\hline 10 Artefatos de couro e calçados & 612 & 10 & 21 & 114 & 758 & 19 \\
\hline 11 Produtos de madeira - exclusive móveis & 592 & 24 & 20 & 179 & 815 & 27 \\
\hline 12 Celulose e produtos de papel & 554 & 22 & 19 & 175 & 769 & 28 \\
\hline 13 Jornais, revistas, discos & 714 & 8 & 13 & 88 & 823 & 13 \\
\hline 14 Refino de petróleo e coque & 317 & 9 & 9 & 269 & 604 & 47 \\
\hline 15 Álcool & 648 & 10 & 9 & 207 & 873 & 26 \\
\hline 16 Produtos químicos & 399 & 13 & 16 & 218 & 646 & 38 \\
\hline 17 Fabricação de resina e elastômeros & 461 & 6 & 20 & 148 & 636 & 27 \\
\hline 18 Produtos farmacêuticos & 733 & 4 & 5 & 54 & 797 & 8 \\
\hline 19 Defensivos agrícolas & 476 & 14 & 26 & 178 & 694 & 31 \\
\hline 20 Perfumaria, higiene e limpeza & 615 & 7 & 19 & 117 & 758 & 19 \\
\hline 21 Tintas, vernizes, esmaltes e lacas & 502 & 7 & 19 & 144 & 673 & 25 \\
\hline 22 Produtos e preparados químicos diversos & 492 & 8 & 32 & 165 & 696 & 29 \\
\hline 23 Artigos de borracha e plástico & 511 & 5 & 25 & 139 & 680 & 25 \\
\hline 24 Cimento & 638 & 19 & 12 & 145 & 814 & 22 \\
\hline 25 Outros produtos de minerais não-metálicos & 635 & 10 & 9 & 120 & 775 & 18 \\
\hline 26 Fabricação de aço e derivados & 601 & 5 & 5 & 145 & 757 & 21 \\
\hline 27 Metalurgia de metais não-ferrosos & 599 & 6 & 5 & 131 & 742 & 19 \\
\hline $\begin{array}{l}28 \text { Produtos de metal - exclusive máquinas e equi- } \\
\text { pamentos }\end{array}$ & 529 & 16 & 19 & 221 & 785 & 33 \\
\hline $\begin{array}{l}29 \begin{array}{l}\text { Máquinas e equipamentos, inclusive manuten- } \\
\text { ção e reparos }\end{array}\end{array}$ & 480 & 19 & 17 & 216 & 731 & 34 \\
\hline 30 Eletrodomésticos . . . & 390 & 25 & 29 & 267 & 711 & 45 \\
\hline $\begin{array}{l}31 \text { Máquinas para escritório e equipamentos de } \\
\text { informática }\end{array}$ & 432 & 8 & 7 & 126 & 573 & 25 \\
\hline 32 Máquinas, aparelhos e materiais elétricos & 548 & 10 & 15 & 145 & 718 & 24 \\
\hline $\begin{array}{l}33 \text { Material eletrônico e equipamentos de comuni- } \\
\text { cações }\end{array}$ & 517 & 6 & 7 & 84 & 614 & 16 \\
\hline $\begin{array}{l}34 \text { Aparelhos/instrumentos médico-hospitalar, } \\
\text { medida e óptico }\end{array}$ & 643 & 12 & 11 & 116 & 782 & 18 \\
\hline 35 Automóveis, camionetas e utilitários & 246 & 45 & 43 & 333 & 666 & 63 \\
\hline 36 Caminhões e ônibus & 324 & 41 & 34 & 287 & 685 & 53 \\
\hline 37 Peças e acessórios para veículos automotores & 473 & 20 & 20 & 211 & 724 & 35 \\
\hline 38 Outros equipamentos de transporte & 537 & 5 & 5 & 84 & 631 & 15 \\
\hline 39 Móveis e produtos das indústrias diversas & 552 & 21 & 23 & 192 & 789 & 30 \\
\hline $\begin{array}{l}40 \begin{array}{l}\text { Eletricidade e gás, água, esgoto e limpeza } \\
\text { urbana }\end{array}\end{array}$ & 848 & 4 & 3 & 42 & 896 & 5 \\
\hline 41 Construção & 749 & 9 & 8 & 83 & 849 & 12 \\
\hline 42 Comércio & 862 & 7 & 4 & 49 & 922 & 6 \\
\hline 43 Transporte, armazenagem e correio & 707 & 9 & 7 & 96 & 820 & 14 \\
\hline 44 Serviços de informação & 834 & 3 & 3 & 30 & 871 & 4 \\
\hline 45 Intermediação financeira e seguros & 844 & 7 & 4 & 49 & 903 & 7 \\
\hline
\end{tabular}


TABELA 2 (CONTINUAÇÃO) - GERAÇÃO DE RENDA DOS SETORES DO PARANÁ PARA A VARIAÇÃO DE R\$ 1 MIL DA DEMANDA FINAL DOS SETORES, EM R\$ DE 2004

\begin{tabular}{l|r|rr|r|r|r}
\multicolumn{1}{c|}{ Setor } & Paraná & $\begin{array}{c}\text { Santa } \\
\text { Catarina }\end{array}$ & $\begin{array}{c}\text { Rio } \\
\text { Grande } \\
\text { do Sul }\end{array}$ & $\begin{array}{c}\text { Restante } \\
\text { do } \\
\text { Brasil }\end{array}$ & $\begin{array}{c}\text { Total } \\
\text { Transbor- } \\
\text { damento } \\
\mathbf{( \% )}\end{array}$ \\
\hline 46 Serviços imobiliários e aluguel & 971 & 2 & 1 & 11 & 985 & 1 \\
47 Serviços de manutenção e reparação & 830 & 6 & 4 & 49 & 890 & 7 \\
48 Serviços de alojamento e alimentação & 633 & 15 & 17 & 152 & 817 & 23 \\
49 Serviços prestados às empresas & 839 & 6 & 5 & 50 & 900 & 7 \\
50 Educação mercantil & 791 & 9 & 5 & 68 & 874 & 9 \\
51 Saúde mercantil & 751 & 8 & 8 & 77 & 844 & 11 \\
52 Outros serviços & 827 & 8 & 5 & 61 & 901 & 8 \\
53 Educação pública & 925 & 2 & 2 & 19 & 948 & 2 \\
54 Saúde pública & 794 & 6 & 4 & 63 & 867 & 8 \\
55 Administração pública e seguridade social & 886 & 3 & 2 & 26 & 917 & 3 \\
Média & 632 & 12 & 13 & 130 & 786 & 20 \\
\hline
\end{tabular}

FONTE: Cálculo dos autores.

Para o Paraná, considerando setores-chave como aqueles com maior valor total de geração de renda, na Tabela 2, pode-se destacar, em valor absoluto, as atividades: 46-Serviços imobiliários e aluguel com $\mathrm{R} \$ 985$ para cada mil reais de variação da demanda final setorial, 53-Educação pública ( \$ 948), 42-Comércio ( $\mathrm{R}$ \$ 922), 55-Administração pública e seguridade social ( $\mathrm{R}$ \$ 917), 45-Intermediação financeira e seguros ( $\mathrm{R}$ \$ 903), 52-Outros serviços ( $\mathrm{R}$ \$ 901) e 49-Serviços prestados às empresas ( $\mathrm{R}$ \$ 900). Os resultados mostraram a importância dos setores relacionados ao comércio e aos serviços na geração de renda. No entanto, deve-se lembrar que esta renda é gerada tanto no setor impactado em sua demanda final quanto em outros setores da economia dentro e fora da região de origem.

Os setores-chave do Paraná, nominados acima, não apresentaram grande transbordamento, relativamente aos demais, significando que o estímulo a estas atividades causaria maior impacto no próprio estado do que em outras regiões. Por outro lado, a indústria automobilística, da qual fazem parte os setores 35, 36 e 37, mostrou transbordamento elevado tanto para o Restante do Brasil quanto para Santa Catarina e Rio Grande do Sul. Cabe salientar o setor 35 que, frente a uma variação de $\mathrm{R} \$ 1$ mil na sua demanda final, geraria $63 \%$ de renda fora do Paraná, sendo 50\% desta gerada no Restante do Brasil. A indústria automobilística no Paraná é um caso típico de cadeia produtiva que demanda bens e serviços intermediários diversos e de diferentes localidades, gerando fluxos inter-regionais importantes ainda em 2004, apesar do seu desenvolvimento pós-abertura comercial. O mesmo ocorreu, porém com menor intensidade, para os setores 6-Alimentos e Bebidas, 9-Artigos do vestuário e acessórios e 30-Eletrodomésticos, pois eles têm maior impacto sobre a renda dos estados do Sul e Restante do Brasil do que outros setores da economia paranaense. O setor 14-Refino de petróleo e coque demandou matéria-prima do Restante do Brasil, com menor impacto sobre a renda dos outros estados da 
Região Sul.

TABELA 3 - GERAÇÃO DE RENDA DOS SETORES DE SANTA CATARINA PARA A VARIAÇÃO DE R\$ 1 MIL DA DEMANDA FINAL DOS SETORES, EM R\$ DE 2004

\begin{tabular}{|c|c|c|c|c|c|c|c|}
\hline & Setor & Paraná & $\begin{array}{c}\text { Santa } \\
\text { Catarina }\end{array}$ & \begin{tabular}{|c|} 
Rio \\
Grande \\
do Sul
\end{tabular} & $\begin{array}{c}\text { Restante } \\
\text { do } \\
\text { Brasil }\end{array}$ & Total & $\begin{array}{c}\text { Transbor- } \\
\text { damento } \\
(\%)\end{array}$ \\
\hline 1 & Agricultura, silvicultura, exploração florestal & 23 & 719 & 15 & 113 & 871 & 17 \\
\hline 2 & Pecuária e pesca & 92 & 444 & 45 & 225 & 805 & 45 \\
\hline 3 & Petróleo e gás natural & 9 & 737 & 8 & 66 & 820 & 10 \\
\hline 4 & Minério de ferro & 9 & 656 & 7 & 153 & 825 & 20 \\
\hline 5 & Outros da indústria extrativa & 16 & 621 & 14 & 132 & 783 & 21 \\
\hline 6 & Alimentos e Bebidas & 76 & 429 & 44 & 264 & 813 & 47 \\
\hline 7 & Produtos do fumo & 22 & 668 & 16 & 108 & 814 & 18 \\
\hline 8 & Têxteis & 29 & 535 & 24 & 212 & 799 & 33 \\
\hline 9 & Artigos do vestuário e acessórios & 38 & 541 & 22 & 228 & 829 & 35 \\
\hline 10 & Artefatos de couro e calçados & 24 & 576 & 32 & 145 & 778 & 26 \\
\hline 11 & Produtos de madeira - exclusive móveis & 51 & 603 & 30 & 141 & 825 & 27 \\
\hline 12 & Celulose e produtos de papel & 29 & 569 & 24 & 166 & 788 & 28 \\
\hline 13 & Jornais, revistas, discos & 10 & 736 & 13 & 79 & 839 & 12 \\
\hline 14 & Refino de petróleo e coque & 25 & 297 & 11 & 307 & 640 & 54 \\
\hline 15 & Álcool & 14 & 791 & 10 & 73 & 888 & 11 \\
\hline 16 & Produtos químicos & 12 & 474 & 14 & 176 & 676 & 30 \\
\hline 17 & Fabricação de resina e elastômeros & 10 & 525 & 22 & 121 & 678 & 23 \\
\hline 18 & Produtos farmacêuticos & 12 & 702 & 12 & 89 & 816 & 14 \\
\hline 19 & Defensivos agrícolas & 23 & 447 & 34 & 216 & 720 & 38 \\
\hline 20 & Perfumaria, higiene e limpeza & 20 & 571 & 20 & 166 & 778 & 27 \\
\hline 21 & Tintas, vernizes, esmaltes e lacas & 40 & 348 & 41 & 265 & 694 & 50 \\
\hline 22 & Produtos e preparados químicos diversos & 16 & 481 & 32 & 168 & 697 & 31 \\
\hline 23 & Artigos de borracha e plástico & 14 & 438 & 42 & 208 & 703 & 38 \\
\hline 24 & Cimento & 10 & 731 & 7 & 79 & 827 & 12 \\
\hline 25 & Outros produtos de minerais não-metálicos & 32 & 561 & 23 & 170 & 786 & 29 \\
\hline 26 & Fabricação de aço e derivados & 9 & 585 & 10 & 172 & 776 & 25 \\
\hline 27 & Metalurgia de metais não-ferrosos & 16 & 545 & 15 & 182 & 758 & 28 \\
\hline 28 & $\begin{array}{l}\text { Produtos de metal - exclusive máquinas e equi- } \\
\text { pamentos }\end{array}$ & 20 & 552 & 28 & 201 & 801 & 31 \\
\hline 29 & $\begin{array}{l}\text { Máquinas e equipamentos, inclusive manutenção } \\
\text { e reparos }\end{array}$ & 29 & 478 & 32 & 216 & 755 & 37 \\
\hline 30 & Eletrodomésticos . . . & 36 & 388 & 36 & 272 & 733 & 47 \\
\hline 31 & $\begin{array}{l}\text { Máquinas para escritório e equipamentos de } \\
\text { informática }\end{array}$ & 9 & 551 & 8 & 69 & 638 & 14 \\
\hline 32 & Máquinas, aparelhos e materiais elétricos & 28 & 480 & 29 & 204 & 741 & 35 \\
\hline 33 & $\begin{array}{l}\text { Material eletrônico e equipamentos de comuni- } \\
\text { cações }\end{array}$ & 15 & 517 & 13 & 112 & 656 & 21 \\
\hline 34 & $\begin{array}{l}\text { Aparelhos/instrumentos médico-hospitalar, } \\
\text { medida e óptico }\end{array}$ & 19 & 638 & 19 & 131 & 806 & 21 \\
\hline 35 & Automóveis, camionetas e utilitários & 16 & 530 & 19 & 142 & 706 & 25 \\
\hline 36 & Caminhões e ônibus & 16 & 547 & 19 & 140 & 722 & 24 \\
\hline 37 & Peças e acessórios para veículos automotores & 23 & 510 & 28 & 189 & 750 & 32 \\
\hline 38 & Outros equipamentos de transporte & 8 & 570 & 10 & 93 & 680 & 16 \\
\hline 39 & Móveis e produtos das indústrias diversas & 28 & 580 & 27 & 169 & 805 & 28 \\
\hline 40 & Eletricidade e gás, água, esgoto e limpeza urbana & 10 & 730 & 7 & 83 & 831 & 12 \\
\hline 41 & Construção & 19 & 723 & 16 & 98 & 855 & 15 \\
\hline 42 & Comércio & 7 & 873 & 5 & 42 & 928 & 6 \\
\hline & Transporte, armazenagem e correio & 14 & 700 & 11 & 107 & 832 & 16 \\
\hline 44 & Serviços de informação & 8 & 824 & 7 & 44 & 883 & 7 \\
\hline 45 & Intermediação financeira e seguros & 6 & 870 & 4 & 29 & 909 & 4 \\
\hline 46 & Serviços imobiliários e aluguel & 1 & 980 & 1 & 7 & 989 & 1 \\
\hline 47 & Serviços de manutenção e reparação & 6 & 852 & 6 & 41 & 905 & 6 \\
\hline 48 & Serviços de alojamento e alimentação & 34 & 598 & 29 & 157 & 818 & 27 \\
\hline
\end{tabular}


TABELA 3 (CONTINUAÇÃO) - GERAÇÃO DE RENDA DOS SETORES DE SANTA CATARINA PARA A VARIAÇÃO DE R\$ 1 MIL DA DEMANDA FINAL DOS SETORES, EM R\$ DE 2004

\begin{tabular}{l|r|r|r|r|r|r}
\hline \multicolumn{1}{c|}{ Setor } & Paraná & $\begin{array}{c}\text { Santa } \\
\text { Catarina }\end{array}$ & $\begin{array}{c}\text { Rio } \\
\text { Grande } \\
\text { do Sul }\end{array}$ & $\begin{array}{c}\text { Restante } \\
\text { do } \\
\text { Brasil }\end{array}$ & $\begin{array}{c}\text { Total } \\
\text { damento } \\
\text { dansbor- } \\
(\mathbf{\%})\end{array}$ \\
\hline 49 Serviços prestados às empresas & 13 & 824 & 11 & 63 & 911 & 10 \\
50 Educação mercantil & 14 & 790 & 10 & 66 & 879 & 10 \\
51 Saúde mercantil & 11 & 762 & 9 & 73 & 855 & 11 \\
52 Outros serviços & 10 & 830 & 8 & 54 & 901 & 8 \\
53 Educação pública & 4 & 933 & 3 & 21 & 960 & 3 \\
54 Saúde pública & 8 & 812 & 6 & 62 & 889 & 9 \\
55 Administração pública e seguridade social & 6 & 888 & 4 & 32 & 930 & 4 \\
Média & 20 & 630 & 18 & 133 & 802 & 21 \\
\hline
\end{tabular}

FONTE: Cálculo dos autores.

Os resultados de geração de renda dos setores de Santa Catarina estão resumidos na Tabela 3. Os maiores valores absolutos pertenceram aos setores comércio e serviços: 46-Serviços imobiliários e aluguel (R \$ 989), 53-Educação pública (R \$ 960), 55-Administração pública e seguridade social ( $\mathrm{R}$ \$ 930), 42-Comércio ( $\mathrm{R}$ \$ 928), 49-Serviços prestados às empresas (R\$ 911), 45-Intermediação financeira e seguros (R \$ 909) e 47-Serviços de manutenção e reparação ( $\mathrm{R}$ \$ 905). Todos estes setores apresentaram valores relativamente menores de transbordamento do que a média (21\%), indicando, assim, que a maior parte da renda gerada permaneceria na região de origem.

Os setores de Santa Catarina com maior transbordamento também podem ser visualizados na Tabela 3: 14-Refino de petróleo e coque (54\%), 21-Tintas, vernizes, esmaltes e lacas (50\%), 6-Alimentos e Bebidas (47\%), 30-Eletrodomésticos (47\%), 2-Pecuária e pesca (45\%), 19-Defensivos agrícolas (38\%), 9-Artigos do vestuário e acessórios (35\%) e 23-Artigos de borracha e plástico $(38 \%)$. É interessante verificar que os setores relacionados ao agronegócio como 2, 6 e 19, apresentaram grande transbordamento para a própria Região Sul, o mesmo ocorre com o setor 9. As cadeias produtivas destes setores foram dependentes de bens e serviços de fora da região de origem, Santa Catarina. Por outro lado, os setores 21, 23 e 14 contribuíram, notadamente, para a geração de renda no Restante do Brasil, com, em média, 39\%.

TABELA 4 - GERAÇÃO DE RENDA DOS SETORES DO RIO GRANDE DO SUL PARA A VARIAÇÃO DE R\$ 1 MIL DA DEMANDA FINAL DOS SETORES, EM R\$ DE 2004

\begin{tabular}{ll|r|r|r|r|r|r}
\hline \multicolumn{1}{c|}{ Setor } & Paraná & $\begin{array}{c}\text { Santa } \\
\text { Catarina }\end{array}$ & $\begin{array}{c}\text { Rio } \\
\text { Grande } \\
\text { do Sul }\end{array}$ & $\begin{array}{c}\text { Restante } \\
\text { do } \\
\text { Brasil }\end{array}$ & $\begin{array}{c}\text { Total } \\
\text { damento } \\
\text { d\%) }\end{array}$ \\
\hline 1 Agricultura, silvicultura, exploração florestal & 16 & 8 & 706 & 92 & 821 & 14 \\
2 & Pecuária e pesca & 35 & 19 & 631 & 152 & 837 & 25 \\
3 & Petróleo e gás natural & 3 & 2 & 792 & 39 & 837 & 5 \\
4 & Minério de ferro & 3 & 2 & 788 & 76 & 869 & 9 \\
5 & Outros da indústria extrativa & 4 & 5 & 762 & 62 & 832 & 8 \\
6 & Alimentos e Bebidas & 25 & 11 & 590 & 173 & 799 & 26 \\
7 Produtos do fumo & 84 & 147 & 352 & 207 & 790 & 55 \\
\hline
\end{tabular}


TABELA 4 (CONTINUAÇÃO) - GERAÇÃO DE RENDA DOS SETORES DO RIO GRANDE DO SUL PARA A VARIAÇÃO DE R\$ 1 MIL DA DEMANDA FINAL DOS SETORES, EM R\$ DE 2004

\begin{tabular}{|c|c|c|c|c|c|c|}
\hline Setor & Paraná & $\begin{array}{c}\text { Santa } \\
\text { Catarina }\end{array}$ & $\begin{array}{c}\text { Rio } \\
\text { Grande } \\
\text { do Sul }\end{array}$ & $\begin{array}{c}\text { Restante } \\
\text { do } \\
\text { Brasil } \\
\end{array}$ & Total & $\begin{array}{c}\text { Transbor- } \\
\text { damento } \\
(\%)\end{array}$ \\
\hline 8 Têxteis & 18 & 22 & 531 & 207 & 777 & 32 \\
\hline 9 Artigos do vestuário e acessórios & 16 & 26 & 580 & 191 & 813 & 29 \\
\hline 10 Artefatos de couro e calçados & 33 & 19 & 454 & 246 & 753 & 40 \\
\hline 11 Produtos de madeira - exclusive móveis & 7 & 4 & 741 & 53 & 805 & 8 \\
\hline 12 Celulose e produtos de papel & 6 & 4 & 697 & 55 & 762 & 9 \\
\hline 13 Jornais, revistas, discos & 11 & 9 & 732 & 65 & 817 & 10 \\
\hline 14 Refino de petróleo e coque & 17 & 5 & 258 & 310 & 590 & 56 \\
\hline 15 Álcool & 9 & 5 & 781 & 62 & 857 & 9 \\
\hline 16 Produtos químicos & 22 & 16 & 386 & 215 & 638 & 40 \\
\hline 17 Fabricação de resina e elastômeros & 17 & 10 & 434 & 170 & 630 & 31 \\
\hline 18 Produtos farmacêuticos & 5 & 3 & 727 & 53 & 789 & 8 \\
\hline 19 Defensivos agrícolas & 19 & 10 & 494 & 168 & 691 & 29 \\
\hline 20 Perfumaria, higiene e limpeza & 12 & 5 & 638 & 98 & 752 & 15 \\
\hline 21 Tintas, vernizes, esmaltes e lacas & 14 & 10 & 504 & 139 & 667 & 24 \\
\hline 22 Produtos e preparados químicos diversos & 9 & 7 & 588 & 89 & 693 & 15 \\
\hline 23 Artigos de borracha e plástico & 15 & 11 & 518 & 132 & 676 & 23 \\
\hline 24 Cimento & 5 & 4 & 742 & 58 & 808 & 8 \\
\hline 25 Outros produtos de minerais não-metálicos & 12 & 11 & 634 & 108 & 765 & 17 \\
\hline 26 Fabricação de aço e derivados & 5 & 4 & 600 & 140 & 748 & 20 \\
\hline 27 Metalurgia de metais não-ferrosos & 6 & 5 & 588 & 132 & 731 & 19 \\
\hline $\begin{array}{l}28 \text { Produtos de metal - exclusive máquinas e equi- } \\
\text { pamentos }\end{array}$ & 11 & 12 & 584 & 174 & 782 & 25 \\
\hline $\begin{array}{l}29 \text { Máquinas e equipamentos, inclusive manutenção } \\
\text { e reparos }\end{array}$ & 16 & 18 & 478 & 216 & 728 & 34 \\
\hline 30 Eletrodomésticos . . . & 5 & 4 & 626 & 74 & 709 & 12 \\
\hline $\begin{array}{l}31 \text { Máquinas para escritório e equipamentos de } \\
\text { informática }\end{array}$ & 18 & 12 & 339 & 198 & 567 & 40 \\
\hline 32 Máquinas, aparelhos e materiais elétricos & 8 & 6 & 585 & 114 & 713 & 18 \\
\hline $\begin{array}{l}33 \text { Material eletrônico e equipamentos de comuni- } \\
\text { cações }\end{array}$ & 5 & 3 & 526 & 74 & 608 & 14 \\
\hline $\begin{array}{l}34 \text { Aparelhos/instrumentos médico-hospitalar, } \\
\text { medida e óptico }\end{array}$ & 10 & 8 & 655 & 106 & 779 & 16 \\
\hline 35 Automóveis, camionetas e utilitários & 8 & 7 & 554 & 97 & 666 & 17 \\
\hline 36 Caminhões e ônibus & 8 & 7 & 572 & 96 & 684 & 16 \\
\hline 37 Peças e acessórios para veículos automotores & 14 & 14 & 520 & 173 & 721 & 28 \\
\hline 38 Outros equipamentos de transporte & 4 & 3 & 553 & 63 & 623 & 11 \\
\hline 39 Móveis e produtos das indústrias diversas & 43 & 29 & 522 & 193 & 786 & 34 \\
\hline 40 Eletricidade e gás, água, esgoto e limpeza urbana & 3 & 1 & 786 & 41 & 832 & 5 \\
\hline 41 Construção & 6 & 5 & 773 & 57 & 841 & 8 \\
\hline 42 Comércio & 5 & 3 & 863 & 40 & 910 & 5 \\
\hline 43 Transporte, armazenagem e correio & 6 & 3 & 746 & 71 & 826 & 10 \\
\hline 44 Serviços de informação & 4 & 4 & 803 & 39 & 850 & 6 \\
\hline 45 Intermediação financeira e seguros & 4 & 3 & 860 & 31 & 898 & 4 \\
\hline 46 Serviços imobiliários e aluguel & 1 & 1 & 976 & 8 & 985 & 1 \\
\hline 47 Serviços de manutenção e reparação & 5 & 5 & 819 & 48 & 877 & 7 \\
\hline 48 Serviços de alojamento e alimentação & 12 & 6 & 725 & 79 & 822 & 12 \\
\hline 49 Serviços prestados às empresas & 3 & 2 & 857 & 22 & 884 & 3 \\
\hline 50 Educação mercantil & 10 & 6 & 795 & 58 & 869 & 8 \\
\hline 51 Saúde mercantil & 9 & 8 & 741 & 82 & 839 & 12 \\
\hline 52 Outros serviços & 8 & 7 & 799 & 63 & 877 & 9 \\
\hline 53 Educação pública & 4 & 3 & 908 & 27 & 941 & 4 \\
\hline 54 Saúde pública & 6 & 5 & 773 & 74 & 858 & 10 \\
\hline 55 Administração pública e seguridade social & 4 & 3 & 865 & 37 & 909 & 5 \\
\hline Média & 12 & 10 & 652 & 106 & 781 & 16 \\
\hline
\end{tabular}

FONTE: Cálculo dos autores. 
A geração de renda dos setores do Rio Grande do Sul e o efeito transbordamento estão apresentados na Tabela 4. As atividades econômicas mais importantes em geração de renda foram: 46-Serviços imobiliários e aluguel ( $\mathrm{R}$ \$ 985), 53-Educação pública ( $\mathrm{R}$ 941), 42-Comércio (R\$ 910), 55-Administração pública e seguridade social (R\$ 909), 45-Intermediação financeira e seguros ( $\mathrm{R}$ \$ 898) e 49-Serviços prestados às empresas ( $\mathrm{R}$ \$ 884). Todos estes setores-chave estão relacionados ao comércio e serviços, com baixo efeito transbordamento.

Os maiores valores percentuais de transbordamento da geração de renda pertenceram aos setores 14-Refino de petróleo e coque (56\%), 7-Produtos do fumo (55\%), 10-Artefatos de couro e calçados (40\%), 16-Produtos químicos (40\%), 31-Máquinas para escritório e equipamentos de informática (40\%), 29-Máquinas e equipamentos, inclusive manutenção e reparos (34\%) e 39-Móveis e produtos das indústrias diversas. Cabe salientar o setor 14 que, frente ao aumento de R \$ 1 mil na sua demanda final, geraria 56\% de renda fora do estado, sendo que 53\%, aproximadamente, seriam gerados no Restante do Brasil.

TABELA 5 - GERAÇÃO DE RENDA DOS SETORES DO RESTANTE DO BRASIL PARA A VARIAÇÃO DE R\$ 1 MIL DA DEMANDA FINAL DOS SETORES, EM R\$ DE 2004

\begin{tabular}{|c|c|c|c|c|c|c|c|}
\hline & Setor & Paraná & $\begin{array}{c}\text { Santa } \\
\text { Catarina }\end{array}$ & $\begin{array}{c}\text { Rio } \\
\text { Grande } \\
\text { do Sul } \\
\end{array}$ & $\begin{array}{c}\text { Restante } \\
\text { do } \\
\text { Brasil } \\
\end{array}$ & Total & $\begin{array}{c}\text { Transbor- } \\
\text { damento } \\
(\%) \\
\end{array}$ \\
\hline 1 & Agricultura, silvicultura, exploração florestal & 13 & 3 & 9 & 824 & 849 & 3 \\
\hline 2 & Pecuária e pesca & 19 & 7 & 11 & 820 & 856 & 4 \\
\hline 3 & Petróleo e gás natural & 11 & 6 & 9 & 761 & 787 & 3 \\
\hline 4 & Minério de ferro & 9 & 4 & 8 & 793 & 814 & 3 \\
\hline 5 & Outros da indústria extrativa & 10 & 7 & 11 & 735 & 763 & 4 \\
\hline 6 & Alimentos e Bebidas & 45 & 16 & 30 & 708 & 798 & 11 \\
\hline 7 & Produtos do fumo & 38 & 66 & 108 & 556 & 768 & 28 \\
\hline 8 & Têxteis & 10 & 5 & 10 & 757 & 781 & 3 \\
\hline 9 & Artigos do vestuário e acessórios & 6 & 6 & 6 & 798 & 816 & 2 \\
\hline 10 & Artefatos de couro e calçados & 14 & 7 & 21 & 703 & 744 & 6 \\
\hline 11 & Produtos de madeira - exclusive móveis & 12 & 5 & 8 & 784 & 810 & 3 \\
\hline 12 & Celulose e produtos de papel & 20 & 10 & 14 & 715 & 759 & 6 \\
\hline 13 & Jornais, revistas, discos & 13 & 6 & 10 & 783 & 814 & 4 \\
\hline 14 & Refino de petróleo e coque & 10 & 4 & 6 & 531 & 551 & 4 \\
\hline 15 & Álcool & 21 & 4 & 8 & 839 & 871 & 4 \\
\hline 16 & Produtos químicos & 10 & 5 & 8 & 603 & 627 & 4 \\
\hline 17 & Fabricação de resina e elastômeros & 8 & 3 & 12 & 596 & 619 & 4 \\
\hline 18 & Produtos farmacêuticos & 17 & 7 & 12 & 749 & 786 & 5 \\
\hline 19 & Defensivos agrícolas & 15 & 5 & 15 & 638 & 673 & 5 \\
\hline 20 & Perfumaria, higiene e limpeza & 23 & 8 & 20 & 694 & 744 & 7 \\
\hline 21 & Tintas, vernizes, esmaltes e lacas & 30 & 8 & 25 & 597 & 660 & 10 \\
\hline 22 & Produtos e preparados químicos diversos & 20 & 8 & 25 & 621 & 674 & 8 \\
\hline 23 & Artigos de borracha e plástico & 19 & 7 & 35 & 599 & 661 & 9 \\
\hline 24 & Cimento & 9 & 6 & 7 & 783 & 805 & 3 \\
\hline 25 & Outros produtos de minerais não-metálicos & 14 & 7 & 9 & 732 & 762 & 4 \\
\hline 26 & Fabricação de aço e derivados & 9 & 7 & 11 & 712 & 739 & 4 \\
\hline 27 & Metalurgia de metais não-ferrosos & 10 & 6 & 9 & 705 & 730 & 3 \\
\hline 28 & $\begin{array}{l}\text { Produtos de metal - exclusive máquinas e equi- } \\
\text { pamentos }\end{array}$ & 10 & 6 & 12 & 751 & 779 & 4 \\
\hline 29 & $\begin{array}{l}\text { Máquinas e equipamentos, inclusive manutenção } \\
\text { e reparos }\end{array}$ & 12 & 7 & 12 & 688 & 720 & 4 \\
\hline
\end{tabular}


TABELA 5 (CONTINUAÇÃO) - GERAÇÃO DE RENDA DOS SETORES DO RESTANTE DO BRASIL PARA A VARIAÇÃO DE R\$ 1 MIL DA DEMANDA FINAL DOS SETORES, EM R\$ DE 2004

\begin{tabular}{|c|c|c|c|c|c|c|}
\hline Setor & Paraná & $\begin{array}{c}\text { Santa } \\
\text { Catarina }\end{array}$ & \begin{tabular}{|c|} 
Rio \\
Grande \\
do Sul \\
\end{tabular} & $\begin{array}{c}\text { Restante } \\
\text { do } \\
\text { Brasil }\end{array}$ & Total & $\begin{array}{c}\text { Transbor- } \\
\text { damento } \\
(\%)\end{array}$ \\
\hline 30 Eletrodomésticos & 11 & 6 & 12 & 672 & 702 & 4 \\
\hline $\begin{array}{l}31 \text { Máquinas para escritório e equipamentos de } \\
\text { informática }\end{array}$ & 9 & 4 & 7 & 517 & 536 & 4 \\
\hline 32 Máquinas, aparelhos e materiais elétricos & 12 & 6 & 13 & 677 & 708 & 4 \\
\hline $\begin{array}{l}33 \text { Material eletrônico e equipamentos de comuni- } \\
\text { cações }\end{array}$ & 11 & 6 & 10 & 545 & 572 & 5 \\
\hline $\begin{array}{l}34 \text { Aparelhos/instrumentos médico-hospitalar, } \\
\text { medida e óptico }\end{array}$ & 8 & 4 & 8 & 758 & 778 & 3 \\
\hline 35 Automóveis, camionetas e utilitários & 18 & 10 & 19 & 591 & 638 & 7 \\
\hline 36 Caminhões e ônibus & 31 & 17 & 28 & 582 & 656 & 11 \\
\hline 37 Peças e acessórios para veículos automotores & 15 & 8 & 14 & 669 & 706 & 5 \\
\hline 38 Outros equipamentos de transporte & 11 & 6 & 12 & 580 & 609 & 5 \\
\hline 39 Móveis e produtos das indústrias diversas & 23 & 13 & 12 & 736 & 783 & 6 \\
\hline 40 Eletricidade e gás, água, esgoto e limpeza urbana & 3 & 2 & 3 & 823 & 830 & 1 \\
\hline 41 Construção & 12 & 7 & 9 & 813 & 841 & 3 \\
\hline 42 Comércio & 3 & 2 & 3 & 896 & 903 & 1 \\
\hline 43 Transporte, armazenagem e correio & 7 & 3 & 6 & 781 & 797 & 2 \\
\hline 44 Serviços de informação & 4 & 2 & 3 & 840 & 850 & 1 \\
\hline 45 Intermediação financeira e seguros & 6 & 3 & 4 & 875 & 887 & 1 \\
\hline 46 Serviços imobiliários e aluguel & 1 & 0 & 1 & 984 & 986 & 0 \\
\hline 47 Serviços de manutenção e reparação & 6 & 4 & 6 & 854 & 868 & 2 \\
\hline 48 Serviços de alojamento e alimentação & 21 & 9 & 15 & 761 & 806 & 6 \\
\hline 49 Serviços prestados às empresas & 5 & 3 & 4 & 862 & 873 & 1 \\
\hline 50 Educação mercantil & 7 & 3 & 4 & 847 & 861 & 2 \\
\hline 51 Saúde mercantil & 10 & 5 & 7 & 805 & 828 & 3 \\
\hline 52 Outros serviços & 8 & 4 & 5 & 861 & 878 & 2 \\
\hline 53 Educação pública & 3 & 2 & 3 & 935 & 943 & 1 \\
\hline 54 Saúde pública & 5 & 2 & 4 & 845 & 856 & 1 \\
\hline 55 Administração pública e seguridade social & 4 & 2 & 3 & 897 & 906 & 1 \\
\hline Média & 13 & 7 & 13 & 738 & 770 & 4 \\
\hline
\end{tabular}

FONTE: Cálculo dos autores.

Para o Restante do Brasil, os resultados para a geração de renda setorial e do efeito transbordamento estão na Tabela 5. Os setores-chave, considerando os maiores valores absolutos e geração de renda, foram: 46-Serviços imobiliários e aluguel (R \$ 986), 53-Educação pública ( $\mathrm{R} \$ 943), 55$-Administração pública e seguridade social ( $\mathrm{R} \$ 906)$, 42-Comércio ( $\mathrm{R} \$ 903)$, 45-Intermediação financeira e seguros $(\mathrm{R} \$ 887)$ e 52 -Outros serviços $(\mathrm{R} \$ 878)$. Estes setores apresentaram pequeno efeito transbordamento, menor do que a média de $4 \%$ dos setores do Restante do Brasil.

O efeito transbordamento é maior para os setores 7-Produtos do fumo (28\%), 6- Alimentos e Bebidas (11\%), 21-Tintas, vernizes, esmaltes e lacas (10\%), 36-Caminhões e ônibus (11\%), 23-Artigos de borracha e plástico (9\%), 22-Produtos e preparados químicos diversos (8\%), 35-Automóveis, camionetas e utilitários (7\%) e 20-Perfumaria, higiene e limpeza (7\%). Cabe salientar o setor 7, que apresentou forte relação com a produção de matéria-prima proveniente dos estados do sul, notadamente, do Rio Grande do Sul, tradicional produtor de fumo, 
uma vez que $28 \%$ da renda gerada neste setor no Restante do Brasil, transbordaria para estes estados.

É interessante observar que houve coincidência nos setores-chave para a geração de renda nas quatro regiões analisadas, a saber: 42-Comércio, 45-Intermediação financeira e seguros, 46-Serviços imobiliários e aluguel, 49-Serviços prestados às empresas, 52-Outros serviços, 53-Educação pública e 55-Administração pública e seguridade social. Estas atividades econômicas se revezaram como mais importantes em cada região, mas diferenciaram-se em valores absolutos e de transbordamento. De forma geral, elas apresentaram efeitos transbordamento menores do que as médias em suas regiões.

Os setores que apresentam maior efeito transbordamento não foram, necessariamente, os mesmos nas quatro regiões analisadas, mas pode-se afirmar que as cadeias produtivas das atividades Refino de petróleo, Indústria automobilística, Agroindústria (Alimentos e Bebidas e Produtos do fumo) e Artigos do vestuário e acessórios foram responsáveis pela maior parte do efeito transbordamento no sentido Sul-Restante do Brasil. Em sentido contrário, pode-se acrescentar Perfumaria, Higiene e limpeza, Tintas, vernizes e químicos diversos e Artigos de borracha e plásticos.

Muitos dos resultados obtidos nesta pesquisa se aproximam dos alcançados por Moretto et al. (2008), Porsse, Peixoto e Palermo (2008) e Sesso Filho, Rodrigues e Moretto (2007), o que permite considerar os trabalhos analisados complementares, respeitando-se, é claro, as diferenças nos períodos estudados e na agregação de setores, além de se constatar que mudanças estruturais ocorrem a médio e longo prazo.

\section{CONSIDERAÇÕES FINAIS}

A partir da análise dos resultados da geração de renda no sistema inter-regional de insumo-produto da Região Sul-Restante do Brasil foi possível concluir que, em 2004, existiu maior interação econômica entre os estados da Região Sul com o Restante do país do que entre eles.

Observou-se a existência de setores-chave comuns entre as regiões, os quais apresentaram pequeno efeito transbordamento, todos pertencentes ao macrossetor comércio e serviços. Por outro lado, foram exatamente os setores desse macrossetor que representaram os maiores geradores de renda nas quatro regiões estudadas, o que mostra a importância do ramo terciário em 2004.

Os setores com os maiores efeitos transbordamento variaram muito de região para região, mas pode-se generalizar os resultados considerando que as cadeias produtivas das ati- 
vidades Refino de petróleo, Indústria automobilística, Agroindústria (Alimentos e bebidas e Produtos do fumo) e Artigos do vestuário e acessórios foram responsáveis pela maior parte do efeito transbordamento dentro do sistema inter-regional Sul-Restante do Brasil em 2004.

Em que pese o efeito transbordamento refletir a geração de renda em outras regiões como fruto do aumento da demanda final dos setores de regiões distintas, ele não deve ser visto como prejudicial ao desenvolvimento regional, uma vez que é resultado do comércio interregional para consumo intermediário que gera efeitos sinérgicos entre as regiões e os setores envolvidos. O conhecimento e a quantificação destas interações é importante para governos e agentes privados no planejamento e implementação de políticas regionais e setoriais que visem estimular ou corrigir distorções na estrutura produtiva local. Assim, embora a presente análise se refira ao ano de 2004, considerando que a estrutura da economia se modifica lentamente, as conclusões aqui apontadas ainda permanecem válidas como orientação de política econômica.

Como sugestão para novos estudos, seria interessante avançar na análise da geração de emprego, impostos e outras variáveis e seus impactos locais e inter-regionais, considerando sistemas de insumo-produto com maior número de regiões e períodos mais recentes.

\section{REFERÊNCIAS}

GUILHOTO, J. J. M.; SESSO FILHO, U. A. Estimação da matriz insumo-produto a partir de dados preliminares das Contas Nacionais. Economia Aplicada. v. 9, n. 2, p. 277-299, abril/jun. 2005a.

GUILHOTO, J. J. M.; SESSO FILHO, U. A. Estrutura produtiva da Amazônia: uma análise de insumo-produto. Belém: Banco da Amazônia, 2005b. 320 p.

IBGE. Instituto Brasileiro de Geografia e Estatística: Estatística. Disponível em: < http:/ /www. ibge.gov.br>. Acesso em: 20/5/2009.

ISARD, W. Interregional and regional input-output analysis: a model of a space-economy. Review of Economics and Statistics, n.33, p. 319-328, 1951.

LEONTIEF, W. Input-Output economics. $2^{a}$ ed. New York: Oxford University Press, 1986. p. 241-260.

LEONTIEF, W. The structure of the American economy. $2^{a}$ ed. ampliada. New York: Oxford University Press, 1951. 264 p.

MILLER, R. E.; BLAIR, P. D. Input-output analysis: foundations and extensions. 2nd ed. New York: Cambrige University Press, 2009. 750 p.

MORETTO, A. C. Relações intersetoriais e inter-regionais na economia paranaense em 1995. 161 f. Tese (Doutorado) - Escola Superior de Agronomia Luiz de Queiroz, Universidade de São Paulo. Piracicaba, 2000.

MORETTO, A. C.; RODRIGUES, R. L.; SESSO FILHO, U. A.; MAIA, K. O Paraná na dinâmica da renda do sistema inter-regional Sul-Restante do Brasil. Economia \& Tecnologia, Curitiba, v. 15, p. 65 - 75, out./dez. 2008. 
PORSSE, A.A.; PEIXOTO, F. C.; PALERMO, P. U. Matriz de insumo-produto inter-regional Rio Grande do Sul-Restante do Brasil 2003: metodologia e resultados. Texto para discussão FEE, Porto Alegre, n.38, ago. 2008. Disponível em: <http://www.fee.rs.gov.br/sitefee/download/tds/038.pdf>. Acesso em: 30/4/2009.

RODRIGUES, R. L.; SESSO FILHO, U. A.; MORETTO, A. C.; BRENE, P. R. A. Interdependência regional da geração de renda no sistema inter-regional Sul-Restante do Brasil. In: ENCONTRO DE ECONOMIA PARANAENSE, 6., 2010, Guarapuava. Anais... Guarapuava, 2010.

SESSO FILHO, U. A.; MORETTO, A. C.; RODRIGUES, R. L.; BALDUCCI, F. L. P.; KURESKI, R. Indústria automobilística no Paraná: impactos na produção local e no restante do Brasil. Revista Paranaense de Desenvolvimento, v. 106, p. 89-111, jan./jun. 2004.

SESSO FILHO, U. A.; RODRIGUES, R. L.; MORETTO, A. C. Produção e emprego no sistema inter-regional Sul-Restante do Brasil: uma aplicação da matriz de insumo-produto. Revista Paranaense de Desenvolvimento, v. 112, p. 93-110, jan./jun. 2007. 